\title{
BRINCADEIRAS LÚDICO-AGRESSIVAS: TENSÕES E POSSIBILIDADES NO COTIDIANO NA EDUCAÇÃO INFANTIL
}

\author{
PLAYFUL-AGGRESSIVE GAMES: TENSIONS AND POSSIBILITIES IN \\ EVERYDAY LIFE IN CHILDHOOD EDUCATION
}
JUEGOS LÚDICO-AGRESIVOS: TENSIONES Y POSIBILIDADES EN EL COTIDIANO DE LA EDUCACIÓN INFANTIL

\author{
Raquel Firmino Magalhães Barbosa*, Rodrigo Lema Del Rio Martins*, \\ André da Silva Mello*
}

Palavras chave: Educação Infantil. Educação Física. Brincadeiras.

\begin{abstract}
Resumo: Este estudo busca compreender as brincadeiras lúdico-agressivas no contexto da Educação Infantil. Trata-se de uma pesquisa etnográfica com observação participante de crianças de três, quatro e cinco anos de idade, em um Centro Municipal de Educação Infantil de Vitória/ES. Foram utilizadas observações, filmagens, fotografias e narrativas de episódios brincantes descritos em diário de campo, em momentos de pátio e em aulas de Educação Física. A análise consistiu na apreciação qualitativa de episódios de interação, visualizada por meio de três categorias: brincadeiras lúdico-agressivas e contexto social; mídia; e movimentos turbulentos. Evidencia a necessidade de abrir espaço no cotidiano infantil para as diferentes maneiras de brincar, sugerindo uma leitura positiva sobre as brincadeiras lúdico-agressivas, como um elemento socializador, autoral e de manifestação da expressividade infantil que se faz presente na cultura de pares das crianças.
\end{abstract}

Keywords: Childhood Education. Physical Education. Play.

Palabras clave: Educación Infantil. Educación Física. Juego.
Abstract: This study aims to understand the playful-aggressive games in the context of Childhood Education. This is an ethnographic study with participant observation of 3-to-5-year-old children at Municipal Center for Childhood Education in Vitória, Espírito Santo, Brazil. It used observations, video, photographs and narratives of playful episodes described in a field diary at playground times at school and in physical education classes. The analysis consisted in qualitative appreciation of interaction episodes through three categories: playful-aggressive games and social context; media; and turbulent movements. It points out the need to open space in children's daily life for different ways to play, suggesting a positive reading on playful-aggressive play as a socializing and individual element and an expression of the child's expressiveness that is present in children's peer culture.

Resumen: Este estudio busca comprender el juego lúdico-agresivo en el contexto de la Educación Infantil. Es una investigación etnográfica con observación participante de niños de tres, cuatro y cinco años de edad, en un Centro Municipal de Educación Infantil en Vitória/ES. Se utilizaron observaciones, filmaciones, fotografías, narrativas y episodios de juego descritos en un diario de campo en momentos de recreo en el patio y clases de Educación Física. El análisis consistió en la evaluación cualitativa de episodios de interacción, vistos a través de tres categorías: juegos lúdicoagresivos y contexto social; medios de comunicación; y movimientos turbulentos. Se hace evidente la necesidad de abrir espacio en la vida cotidiana de los niños para las distintas maneras de jugar, lo que sugiere una lectura positiva sobre los juegos lúdico-agresivos, como un elemento de socialización, autoral y de manifestación de la expresividad infantil que está presente en la cultura de pares de los niños.
*Universidade Federal do Espírito Santo. Vitória, ES, Brasil. E-mail: kekelfla@yahoo.com.br.

Recebido em: 06-06-2016 Aprovado em: 14-02-2017

(c) (1) (8) Licence 


\section{INTRODUÇÃO}

Brincar é uma das principias expressões do comportamento infantil. Por meio dos jogos e das brincadeiras, a criança interage com o seu meio físico e social, constrói conhecimentos, internaliza e produz cultura e também cria e afirma o seu modo peculiar de ser e estar no mundo. Devido à sua importância para as crianças, o brincar é considerado eixo central do trabalho pedagógico na Educação Infantil, articulando diferentes linguagens e experiências curriculares nessa primeira etapa da Educação Básica (BRASIL, 2016).

Freire (2005) afirma que não é a atividade em si que define o caráter lúdico do jogo ou da brincadeira, mas a maneira subjetiva como as crianças se relacionam com essas manifestações culturais. Quando brincam, as crianças constroem, por meio de sua "cultura de pares", ${ }^{1}$ diferentes modos de jogar e brincar, que dificilmente são compreendidos por um observador externo, mas que conferem a elas coesão e sentido. Portanto, atribuir centralidade às crianças na Educação Infantil implica, necessariamente, considerar as suas produções culturais mediadas pelos jogos e brincadeiras.

Dentre as inúmeras formas de brincar produzidas pelas crianças, estão as "brincadeiras lúdico-agressivas", que se caracterizam por alguma contenda ou confronto de natureza simbólica e corporal. Geralmente, essas manifestações lúdicas são coibidas no contexto escolar, sob o argumento de que elas são prejudiciais às crianças, pois geram violência (CANDREVA et al., 2009). Em sentido contrário a essa visão, Farias, Wiggers e Viana (2014), Barbosa (2011) e Jones (2004) pesquisaram o papel dessas brincadeiras no extravasamento das emoções infantis, no processo de apropriação e ressignificação da realidade e na produção de sentidos para as atividades lúdicas.

Apesar da proibição, as crianças resistem e, de maneira "sorrateira e subversiva", brincam longe do olhar do adulto de lutinha, de mocinho e bandido e de heróis e vilões. Para Finco e Oliveira (2011, p. 72), em que pese

[...] toda bagagem de estereótipos, as crianças pequenas ainda encontram espaços para a transgressão, para a superação e para expressão dos seus desejos. Assim, as crianças pequenas, com seus corpos e com suas espontaneidades, problematizam e questionam esses modelos centrados no adulto [...].

Mas, afinal, qual é o papel das brincadeiras lúdico-agressivas para as crianças? Quais são os sentidos que elas atribuem a essas brincadeiras? É possível sinalizar apontamentos para que as brincadeiras lúdico-agressivas possam ser apropriadas pela Educação Física nas intervenções pedagógicas na Educação Infantil? A fim de responder a essas questões, o objetivo deste artigo é compreender os sentidos construídos pelas crianças nas brincadeiras lúdicoagressivas vivenciadas na Educação Infantil. Para tanto, inserimo-nos no cotidiano de um grupo de crianças em um Centro Municipal de Educação Infantil (CMEI) de Vitória/ES, acompanhando as suas brincadeiras em momentos espontâneos e em aulas de Educação Física.

\section{DELINEAMENTO METODOLÓGICO}

Realizamos uma pesquisa etnográfica para compreender os sentidos produzidos pelas crianças nas brincadeiras lúdico-agressivas em um CMEI em Andorinhas, bairro de 
classe média baixa de Vitória/ES. Observamos as brincadeiras infantis nos momentos livres, sem a intervenção dos adultos, e nas aulas de Educação Física, pois foi nesse contexto que as brincadeiras lúdico-agressivas tiveram maior recorrência. Permanecemos no contexto pesquisado por dez meses, frequentando o cotidiano dessa unidade de ensino quatro vezes por semana, totalizando 160 inserções no campo. Focalizamos as práticas de 60 crianças das turmas/grupos de três, quatro e cinco anos de idade. ${ }^{2}$

Adotamos a postura de observação participante, em que nos envolvemos com 0 grupo social na escola, participando ativamente do seu cotidiano. Essa observação seguiu os princípios da "entrada reativa", proposta por Corsaro (2011), em que o pesquisador se insere de maneira discreta e não invasiva nos ambientes infantis, esperando que as crianças reajam à sua presença. Os diálogos com elas foram se tornando frequentes e, gradativamente, fomos conquistando o status de "adultos atípicos" (CORSARO, 2011), pois não estabelecemos relações assimétricas de poder com as crianças.

Na produção dos dados, utilizamos como fontes o diário de campo, imagens iconográficas (paradas e em movimento) e a "enunciação" - falas em ato (CERTEAU, 1994) - extraídas das interações com as crianças. $\mathrm{Na}$ interpretação dos dados, utilizamos a análise qualitativa de "episódios de interação", desenvolvida por Pedrosa e Carvalho (2005). Focalizamos os elementos que integram a construção das experiências significativas e evidenciamos a narrativa de episódios relacionados com as brincadeiras lúdico-agressivas. Nesse sentido, selecionamos alguns fatos que ocorreram durante a pesquisa de campo e que sintetizam 0 conjunto de situações observadas. Agrupamo-los nas seguintes categorias: brincadeiras lúdico-agressivas e contexto social; mídia; e movimentos turbulentos. Esses episódios não foram os únicos observados, mas são expressivos em relação às categorias que representam.

\section{BRINCADEIRAS LÚDICO-AGRESSIVAS E CONTEXTO SOCIAL}

Ressaltamos que a maioria das crianças reside próximo à escola e está sujeita às influências desse ambiente. O CMEI está localizado numa comunidade em zona de conflito de Vitória/ES, onde o tráfico de drogas, disputa de território e os constantes embates entre policiais e bandidos fazem parte do dia a dia dos moradores (LIRA, 2015).

Segundo Corsaro (2011), partindo do ponto em que as crianças afetam e são afetadas pela sociedade, por fazerem parte dessa categoria estrutural, questionamos: como a agressividade pode repercutir nas brincadeiras infantis?

Observamos, durante a pesquisa, que as situações do cotidiano que as crianças vivem se integram às suas brincadeiras. A narrativa abaixo, com crianças do Grupo VI, demonstra essa articulação:

Durante uma brincadeira no pátio, aproximei-me de três meninas e perguntei: Do que
vocês estão brincando? Uma delas respondeu: Estamos brincando de mãe e filha.
Em seguida, elas iniciaram a narrativa da brincadeira. Uma das meninas começou
a explicar: Eu sou a filha mais velha; essa aqui é a bebê. Ela é filha também e o
nosso pai morreu. Eu falei: Morreu? Morreu de quê? Entusiasmada com a gravação,
elas não relutaram em responder. Uma delas disse: Ele morreu na viagem. A outra
complementou: Ele saiu de casa e um caminhão quase o atropelou. Aí, ele achou
um ônibus para entrar para viajar. Ele ia descer do ônibus, mas um homem mandou

2 As crianças dos CMEI de Vitória/ES são divididas por grupo/faixa etária: Grupo IV - crianças de três a três anos e onze meses de idade; Grupo V - crianças de quatro a quatro anos e onze meses de idade; Grupo VI - crianças de cinco anos a cinco anos e onze meses de idade. 
ele botar a mão na cabeça, fez assim com a arma, atirou e ele morreu. As outras meninas complementavam a narrativa: Foram 50 tiros nele, aqui, na cabeça, e em todo lugar. Eu falei: Caramba, e agora? Uma das meninas respondeu: Aí, eu estou aqui, fazendo comida e tomando banho sozinha... Antes, a gente tomava banho com a nossa mãe, mas agora a gente faz tudo sozinha. Por conta da ausência da mãe na história, eu questionei: Minha nossa! Mas e a mãe de vocês, cadê ela? Uma delas respondeu: Morreu também, vou te contar como foi: ela ia para o trabalho e um caminhão passou por cima dela, atropelou e depois um homem deu 80 tiros nela. Perguntei: Mas, quem atirou nela? Uma das meninas respondeu: Foi o meu tio. Ele era ladrão e não gostava dela (DIÁRIO DE CAMPO, 3-11-2015).

Nesse relato, percebemos que as crianças operaram com o contexto social. Elementos do cotidiano, como armas, tiros, ladrões e comportamentos que esboçam abordagens policiais fizeram parte do mundo simbólico das brincadeiras, como "[...] um reflexo dos valores e das práticas das comunidades e das culturas locais e mais amplas em que elas emergem" (CORSARO, 2011, p. 193).

Entretanto, a relação brincante entre elas apontou para um discurso agressivo e, ao mesmo tempo, lúdico em suas práticas corporais, pois percebemos um fortalecimento de alianças entre os pares e de espaços para criações e válvulas de escape (JONES, 2004; CORSARO, 2011).

Notamos também que esse tipo de articulação parece ser valorizado na cultura de pares, principalmente pelo fato de as crianças se envolverem e compartilhar seu universo sociocultural, sobre pontos que todas conhecem, levando a um contexto de pertencimento do grupo. Por isso, podem contribuir com suas narrativas, simultaneamente, reais e imaginativas, o que revela um contexto de afirmação das identidades infantis dentro de uma cultura de jogo específica, altamente comunal e simbólica (SUTTON-SMITH, 2001).

Nesse sentido, a brincadeira lúdico-agressiva se vincularia às representações da própria realidade das crianças, pois elas interpretam e compartilham esses momentos brincantes dentro do contexto social de seu cotidiano. Outra fonte de dados evidencia uma brincadeira com a imitação de gestos agressivos de crianças do Grupo V:

Em uma aula de Educação Física, notei que algumas crianças começaram a imitar o formato de arma com as mãos, apontavam umas para as outras, fingiam que atiravam, outros fingiam que morriam e permaneceram com a brincadeira por alguns poucos minutos. Quando a professora viu, logo interveio e falou: O que é isso? Pode brincar disso aqui? Um dos meninos respondeu prontamente: Não, tia, não é uma arma, é uma borboleta! A professora, a surpresa com a resposta, disse: Ah, é uma borboleta... Tem certeza? Então, tá bom! Mesmo com a repreensão, as crianças continuaram a brincar de atirar, mas agora sentadas atrás de outras crianças, como uma maneira de fugir do olhar da professora (DIÁRIO DE CAMPO, 8-4-2015).

Com o episódio do gesto de armas, notamos que a percepção da professora quanto às ações brincantes das crianças a conduziu a uma visão de reprodução de comportamentos agressivos. Embora a violência esteja muito presente no cotidiano e no imaginário das crianças, em nossa análise - percebendo as pistas deixadas pela professora e pelas crianças -, ao invés de reforçar a dimensão negativa da agressividade, entendemos que esse fenômeno, no contexto brincante, assume uma perspectiva de manifestação de elementos do cotidiano juntamente com aspectos desafiantes, simbólicos e transgressores, direcionando as relações e as ações para uma forma de expressar-se ludicamente. 
É no brincar que as crianças põem em prática toda a sua subjetividade, seu arcabouço cultural e suas experiências vivenciadas em sua realidade, explorando-as e (re)construindo-as durante a brincadeira. Em relação às atividades mais enérgicas, de conflito e de contato físico entre as crianças, o que acontece é que "[...] geralmente só levamos em conta os aspectos externos da violência, as manifestações e expressões múltiplas, que remetem a fatores [...] sobre os quais o homem parece não ter qualquer domínio [...]" (DADOUN, 2008, p. 8). Tal fato sugere que a direção do olhar do adulto remete somente para uma "concepção eruptiva de violência" (DADOUN, 1998). Entretanto, deixamos de considerar se há espaço lúdico para a manifestação simbólica da agressividade na brincadeira. Sendo assim, consideramos que a forma como as crianças se relacionam com esse fenômeno é o que vai ditar a dimensão dessa manifestação, isto é, os limites que separam o jogo da fronteira do não jogo. Para Zaluar (1999, p. 8), o sentido violento das ações humanas provoca certa ambiguidade, pois "[...] não é possivel, portanto, de antemão, definir substantivamente a violência como positiva e boa, ou como destrutiva e má".

Todavia, a conjuntura dos acontecimentos descritos reforça que a todo tempo a agressividade dos gestos das crianças esteve tangenciada pela fantasia, que deu vigor ao episódio brincante e foi marcada pela lógica infantil, como uma maneira particular de pensar e demonstrar originalidade e espontaneidade em suas performances, "[...] com a capacidade de inventar outra realidade, com temporalidades e lógicas próprias" (FARIA; FINCO, 2011, p. 4-5). Esse episódio demonstrou que em momento algum foi causado prejuízo ou sofrimento às crianças, porém foi privilegiada a representação de manifestações lúdicas para potencializar 0 brincar.

Dentro da perspectiva de repreensão das ações e das lógicas infantis e por não ter espaço para esse tipo de manifestação brincante na escola, percebemos que, embora a brincadeira tenha surgido de forma espontânea e envolvente e, diante das regras impostas e do questionamento da professora, as crianças tiveram que utilizar comportamentos "táticos", entendidos como uma maneira de operar em um contexto "[...] desenvolvido e insinuado dentro de redes de vigilância [...]" (CERTEAU, 1994, p. 175). Dessa maneira, a solução foi camuflar a brincadeira: a arma virou borboleta.

Vale destacar a contribuição de Jones (2004) sobre conhecer o que as crianças vivenciam em seu cotidiano e o que trazem para dentro da escola em suas brincadeiras:

[...] demonstram que brincar tem muitas outras funções — uma delas é permitir às crianças que finjam ser o que sabem que nunca serão. Explorar o que é impossível, perigoso demais ou proibido, para elas, em um contexto controlado e seguro, é uma ferramenta importante para que aceitem os limites da realidade. Brincar com o ódio é uma maneira valiosa de reduzir seu poder. Ser mau e destrutivo na imaginação é uma compensação vital para a loucura a que todos nós precisamos nos submeter se quisermos ser uma pessoa boa (JONES, 2004, p. 12).

Assim, quando as crianças brincam com a sua própria agressividade, talvez a utilizem como uma saída para lidar com a sua própria realidade e/ou vivenciar um contexto de faz de conta. É um momento em que elas se afastam de tudo que as incomoda e entram no seu universo brincante, como se a brincadeira lúdico-agressiva representasse um "antídoto" para a violência na brincadeira, atuando contra a ação de algo nocivo no contexto brincante, isto é, brincar com comportamentos agressivos é uma forma de evitar essa atitude, aludindo a Jones (2004). Isso possibilita conhecer e legitimar as experiências infantis, as suas interações, bem como o reconhecimento da criança como produtora de cultura em seus momentos brincantes. 


\section{BRINCADEIRAS LÚDICO-AGRESSIVAS E MÍDIA}

Durante a pesquisa, outro ponto de destaque foi o desejo de brincar sob a influência de desenhos animados. Em relação aos aspectos simbólicos da cultura infantil, Corsaro (2011, p. 134) afirma existir "[...] três fontes primárias da cultura simbólica da infância: a mídia dirigida à infância (desenhos, filmes e outros), a literatura infantil (especialmente os contos de fadas) e os valores míticos e lendas (Papai Noel, a Fada do Dente e outros)". O referido autor defende que a inserção desses elementos na brincadeira é objeto de apropriação, de manipulação e de representação.

Quando o autor aponta para a mídia dirigida à infância, englobando, principalmente, desenhos animados e filmes, destacamos que, à medida que elas assistem, elas brincam, atribuem sentido aos personagens, criam enredos e aumentam seu capital cultural lúdico, trazendo os "[...] itens específicos da cultura simbólica que as crianças possuem e compartilham em suas culturas de pares" (CORSARO, 2011. p. 134), como observado em uma brincadeira desenvolvida por crianças do Grupo VI, descrita no excerto a seguir:

Cinco crianças corriam atrás de um menino. Ele foi capturado e levado para a casinha do pátio. Lá, elas o colocaram dentro da casinha como se fosse uma espécie de prisão, enquanto os outros permaneceram na porta e na janela para vigiar o 'prisioneiro'. Tempos depois, iniciaram uma luta entre os integrantes da brincadeira. Em seguida, foram chegando mais crianças - dentre elas, meninos e meninas - adentrando o espaço para participarem da brincadeira de lutinha, ao mesmo tempo em que eram observadas por outras crianças pela janela da casinha. Nesse momento, no ápice da interação, notei que se transformaram em superheróis e lutavam contra os vilões. Cada criança escolhia seu personagem e usava seus respectivos poderes. Eram nítidos os movimentos de socos, de chutes, de improvisações verbais, de falas de personagens de desenhos animados, de 'envio de poderes' imaginários, de simulação de mortes, de arremessos voluntários de seus próprios corpos no chão e de sonorização de barulhos de contato físico (DIÁRIO DE CAMPO, 25-6-2015).

A experiência desse episódio é marcada por brincadeiras que envolvem um enredo de faz de conta, de agressividade, de lutas corporais e simulação de prisões e de mortes. Todavia, essas ações se realizam dentro do espaço brincante. Assim, esses elementos vão compondo a cultura lúdica infantil que, para Brougère (2008, p. 50), é constituída por "[...] brincadeiras conhecidas e disponíveis, de costumes lúdicos, de brincadeiras individuais, tradicionais ou universais [...] e geracionais".

Barbosa (2011) reforça essa ideia, quando discute o modo como as crianças operam com seu imaginário para tornar a brincadeira mais atraente e atender aos seus interesses e expectativas. A autora observou a relação da criança com os jogos e as brincadeiras produzidas na cultura de pares infantil, a partir da influência dos desenhos animados. $O$ estudo mostrou que as crianças são ativas em relação ao que veem, no sentido de se apropriar, compartilhar e brincar com seus pares sobre o conteúdo midiático dos desenhos animados. Brougère (2008) acrescenta que é necessário que a criança se aproprie dos elementos midiáticos para que eles possam fazer parte da cultura de pares infantil e a brincadeira faça sentido.

Pelas ficções, pelas diversas imagens que mostra, a televisão fornece às crianças conteúdos para as suas brincadeiras. Elas se transformam, através das brincadeiras, em personagens vistos na televisão [...] Contudo, não basta que as imagens sejam apresentadas na televisão, nem mesmo que elas agradem, para gerar brincadeiras: 
é preciso que elas possam ser integradas ao universo lúdico da criança, às estruturas que constituem a base dessa cultura lúdica [...] (BROUGÈRE, 2008, p. 53).

Pensando sobre essa forma de comunicação, as imagens a que as crianças têm acesso são representadas em sua realidade brincante, conferindo um aspecto específico, quando os elementos midiáticos são incorporados à brincadeira e podem ser revestidos e atualizados por novas ações, contextos e conteúdos. Por esse ângulo, a agressividade representada na brincadeira dá suporte às suas ações e elas se adaptam, de modo coletivo, à estrutura brincante, incorporando no jogo a simulação, a imaginação e a excitação, por meio dos confrontos gerados ludicamente.

\section{BRINCADEIRAS LÚDICO-AGRESSIVAS E MOVIMENTOS TURBULENTOS}

Em momentos de pátio na rotina escolar, notamos que as crianças interagem de diferentes formas no contexto pesquisado, contudo percebemos também uma intensificação de brincadeiras com ações mais enérgicas. No período de "recreio", as brincadeiras são livres de direcionamentos pedagógicos por adultos, propiciando às crianças oportunidade de formular práticas brincantes independentes.

Por isso, há necessidade de se ter um olhar atento para a "rotina cultural" na escola que denota um conjunto de "[...] atividade recorrente e previsível, através da qual a cultura é gerada, adquirida, mantida e refinada" (CORSARO, 2011, p. 175). Assim, a brincadeira e 0 protagonismo infantil ocupam um lugar de destaque nesse cenário.

Nesse contexto, observamos um ponto importante, o sentido dado pelas crianças em relação à casinha do pátio e às brincadeiras que lá acontecem. Esse espaço tem uma conotação diferenciada, pelo fato de elas agirem nesse local com práticas corporais mais enérgicas e com obediência a outras ordens, não impostas pelo adulto, porém criadas e vigiadas pelas próprias crianças nos momentos brincantes. Por essa razão, denominamos esse espaço apropriado de significados e "praticado" pelas crianças de "casinha da transgressão", que, na visão de Certeau (1994, p. 71), está "[...] submetido à organização dinâmica e complexa" aberta pela "tática" dos sujeitos. A Imagem 1 mostra algumas crianças observando as brincadeiras de lutas que acontecem dentro da casinha.

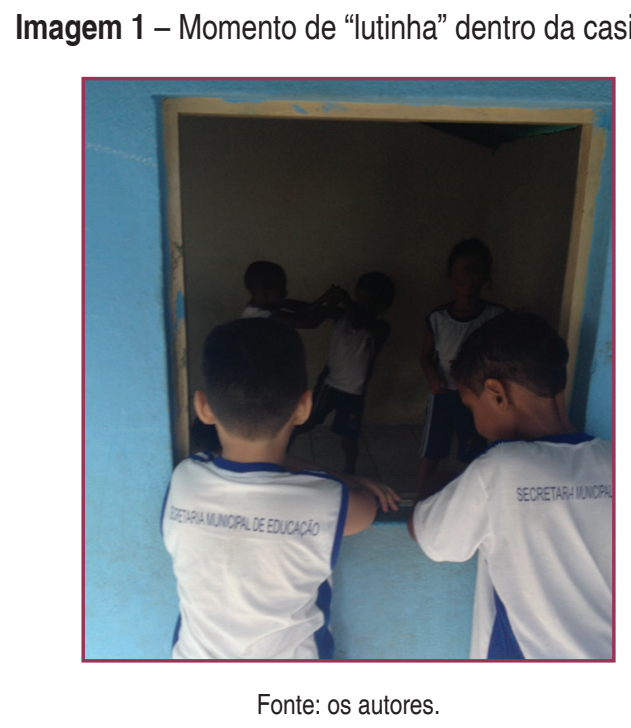


Em um diálogo com as crianças, perguntamos sobre as brincadeiras que acontecem na casinha. Notamos uma relação de pertencimento com o espaço, de socialização de ações brincantes e de construção de identidades, como observado no relato sobre os meninos do Grupo Vl:

Em um momento de pátio, iniciei uma conversa com as crianças sobre a casinha: Como vocês brincam na casinha? Um menino respondeu prontamente: De guerra e de luta. Questionei: Vocês não se machucam? E outro menino respondeu: Não, a gente brinca de pegar os bandidos e luta com eles... eu quero ser fortão... Eu perguntei: Mas pode brincar de lutinha em outro lugar? E o mesmo menino respondeu: Só pode brincar de lutinha na casinha, porque a tia não pode ver. Eu falei: $E$ se ela ver, o que acontece? Ele respondeu: Ela bota de castigo... porque não pode brincar de lutinha, aí a gente vai lá para a casinha para brincar, entendeu? Em busca de saber mais sobre 0 assunto, fiz outra pergunta: $E$ eu posso ver vocês brincando assim lá, na casinha? Eles me responderam: Sim, pode, porque você só gosta de gravar (DIÁRIO DE CAMPO, 30-6-2015).

Nesse espaço, elas veem a possibilidade de a brincadeira ocorrer, reservada do olhar dos profissionais do CMEI. Entretanto, tivemos a oportunidade de ter acesso a esse ambiente, pelo fato de termos tido a aceitação do grupo e o reconhecimento de ser um "adulto atípico". As crianças nos veem filmando, mas não param de brincar, pois sabem que não vamos interferir.

Chegamos à conclusão de que as crianças apresentam comportamentos fervilhantes nesse local por estarem longe do olhar do adulto e poderem brincar sem o risco de sanção. Agem "taticamente" nas brechas do poder, no espaço-tempo não vigiado, porém, sem perder de vista o objetivo brincante, "[...] pode-se dizer que a tática está em movimento permanente (capta no voo) para conferir legitimidade no campo do outro, o que the garante um não-lugar estratégico" (CERTEAU, 1994, p. 47).

Ao observá-las, notamos também que as brincadeiras são construídas dentro de um contexto de interação corporal com movimentos turbulentos. Diante de uma criança que apresenta comportamentos não convencionais (turbulentos, transgressores e agressivos) e que nem sempre fazem sentido em frente às regras estabelecidas pelos adultos, é possível pensar em olhares e em ações que vão restringir esse cenário brincante, pois supomos que condutas como essas normalmente são reprimidas e podem ser consideradas um entrave para a imposição da ordem ao grupo infantil, mesmo que não representem riscos para a integridade das crianças e não gerem queixas. Percebemos esse fato no relato abaixo com brincadeiras do Grupo Vl:

Em um momento de pátio, cerca de seis meninos brincavam de 'lutinha', encenando movimentos de socos e de chutes, gritos e expressões de entusiasmo. Os movimentos foram se desenvolvendo até chegar a uma atividade dentro da atividade. Os postes, que seguram o toldo do pátio, se configuraram como um brinquedo para fazerem rodopios em duplas e até em trios, com o objetivo de otimizar as lutas que estavam realizando. Esse se tornou o ponto alto da brincadeira. Era nítido o desejo de continuar participando ativamente da atividade criada por eles. Esboçavam força, vertigem, vontade de lutar e serem jogados no chão, repetidamente. Entretanto, essa atividade teve a intervenção da professora, pois as crianças estavam brincando muito próximas às educadoras. Uma delas solicitou que parassem de se comportar daquela forma. Logo a brincadeira se dissipou ali, então, foram brincar em outro espaço (DIÁRIO DE CAMPO, 28-82015). 
Assim, a experiência de brincar de lutinha permite que haja a presença da agressividade dentro da agressividade. Dadoun (1998, p. 62) esclarece que esse processo leva os sujeitos envolvidos a uma "violência desacelerada", que implica

[...] diversas formas de violência chocando-se e enlaçando-se umas às outras, provocam reciprocamente captação e inibição; de algum modo, toda violência funciona como uma forte resistência a outra violência que ela tende a fixar; as violências se consomem, uma dentro da outra, e o resultado, então, é uma violência desacelerada.

Diminuindo esse comportamento agressivo, há a formulação de limites para a ação dos indivíduos, prevalecendo outra atmosfera. Nesse caso, a brincadeira começa a se delimitar com fronteiras lúdicas combinadas pelos pares. Isso mostra a proteiformidade brincante. ${ }^{3}$ Mesmo em um cenário de desordem e de incoerência, organizado dentro de uma linha tênue, há a junção de trocas e de acordos, desacelerando quaisquer comportamentos violentos que possam levar ao fim da brincadeira.

Acreditamos que essas linguagens são próprias da infância, pois parece que as crianças necessitam brincar articulando a força, o contato físico, a agressividade, a transformação e a irracionalidade nas histórias criadas para compor suas brincadeiras. Reforçando esse argumento, os dados mostraram que brincadeiras com essas características são vistas a todo tempo no pátio, como explicitado na Imagem 2:

Imagem 2 - Ações corporais de luta na brincadeira

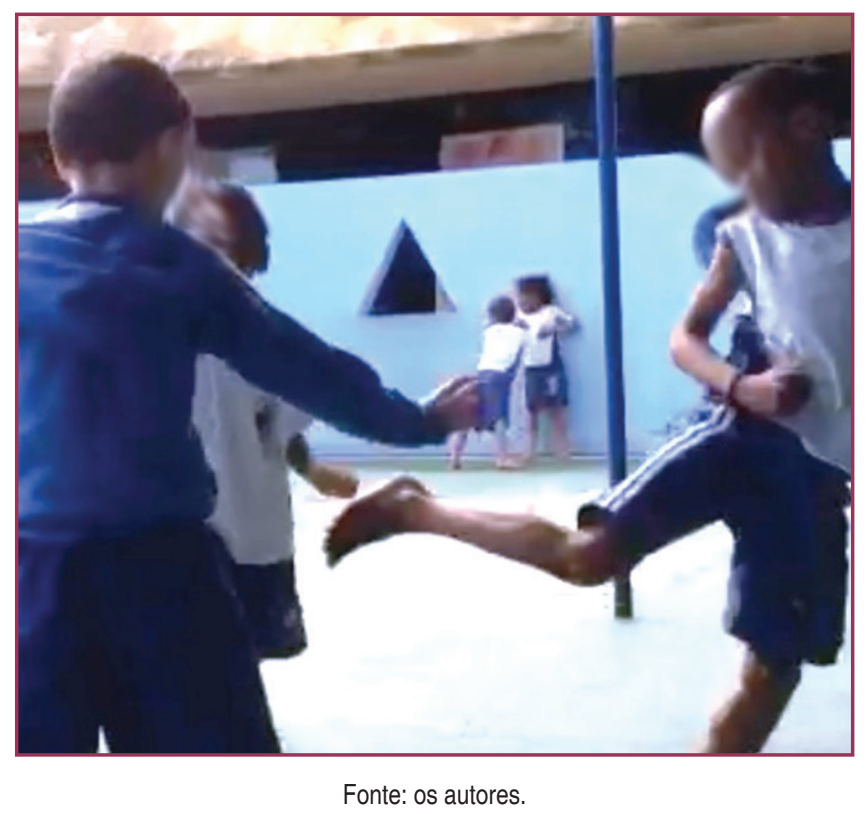

Ao fundo da cena, aparecem duas crianças brincando de empurra-empurra. Lutavam uma contra a outra, testando suas forças com movimentos de se empurrar até alguém conseguir chegar a um determinado ponto ou algum membro da dupla desistir. Demonstravam expressões de alegria, de provocação, de rivalidade e, muitas vezes, até de dor, pela força que faziam. Nesse caso, a brincadeira estava associada ao poder, à força e à competição.

No foco central da imagem, outras crianças brincavam de lutinha, como uma maneira de extravasar e de manifestar a sua linguagem corporal. Desse modo, a interação na

3 Sutton-Smith (2001) compreende o termo proteiforme como algo que se metamorfoseia e se transforma, com características de desconstrução e flexibilidade. 
brincadeira permitiu que elas construíssem regras, obedecessem às normas estabelecidas, administrassem conflitos, resolvessem situações-problema e vivenciassem linguagens e comportamentos idiossincráticos. Nesses entrelaçamentos de ações lúdicas e fantasiosas, elas atribuem sentidos às suas brincadeiras. Com o intuito de explicar o que é vivenciado nesses momentos, Brougère (2008, p. 78), quando trata de brincadeiras de guerra, destaca que

[...] a brincadeira é, também, confrontação com a violência do mundo, é um encontro com essa violência em nível simbólico [...], aparece como um meio de escapar da vida limitada da criança, de se projetar num universo alternativo excitante [...], a guerra é uma das principais fontes da exploração, da aventura, da ruptura com o cotidiano.

Nesse sentido, conforme percebido durante a pesquisa, as linguagens infantis demonstram emoções, comportamentos, movimentos, inventividades e ruptura com 0 cotidiano em meio à ludicidade de suas ações. Juntamente a isso, elas também manifestam comportamentos agressivos e de nonsense durante o jogo. É possível observar esses aspectos, quando as crianças estão em seus momentos brincantes, com ações aparentemente ambíguas, sem sentido e repreensíveis, na visão do adulto, porém, com muito significado para quem faz parte do contexto brincante.

Sutton-Smith (2001) compreende o termo nonsense pelo aspecto da incoerência, da inversão, do sem sentido, da desconstrução, da irracionalidade e da transformação. Certeau (1994, p. 69) complementa que a palavra nonsense tem um sentido do que não é aceitável, algo sem limites e que possui um "[...] caráter irreceptível (o nonsense) de toda sentença que tenta uma saída para aquilo que não se pode dizer". Assim sendo, entendemos que a razão e a desrazão caminham lado a lado nas brincadeiras, sem uma anular a outra e, ao mesmo tempo, apresentam uma lógica própria, dentro de uma realidade peculiar, que desafia e discute a realidade que temos como normal.

Nessa lógica, a criança liga o real ao irreal e faz a junção do prazer, da ludicidade e do nonsense, próprios da dimensão estética, que se expressa em uma "[...] proliferação criadora de imagens que vai se manifestar na invenção de novas formas e de seres fantásticos. Com 0 aparecimento do homem imaginário, acrescenta-se indissoluvelmente 0 aparecimento do homem imaginante" (MORIN, 1975, p. 110).

Ao analisar as categorias sobre brincadeiras infantis lúdico-agressivas, foi possível perceber a articulação entre as rubricas da ludicidade, da agressividade e do nonsense, no que concerne à seriedade e ao arrebatamento das ações brincantes, à violência desacelerada nas trocas lúdicas, à capacidade em agir com a subjetividade, à fantasia e à desrazão.

\section{CONSIDERAÇÕES FINAIS}

Os resultados apresentaram uma leitura positiva em relação à manifestação lúdicoagressiva na brincadeira. Ao "mergulharmos" nas experiências infantis, constatamos que as suas interações podem oportunizar a compreensão de outras facetas da brincadeira, a (des) configuração de cenários brincantes e o reconhecimento de entrelaçamentos (im)possíveis.

Considerando as práticas infantis na articulação com as rubricas brincantes, percebemos que as brincadeiras lúdico-agressivas se corporificam por meio de ações, interações e relações que evidenciam a prevalência de elementos lúdicos juntamente com a busca de excitação, 
de poder, de combate, de nonsense, de agressividade, de transgressão e de transformação. Supomos que seja uma maneira de as crianças se expressarem ludicamente e ressignificar a cultura da qual fazem parte.

Dessa forma, a agressividade não repercute de forma negativa, levando as crianças a brigar, a entrar em um contexto de não jogo e a causar sofrimento ao colega. Isso se confronta com a visão tradicional de que a agressividade deve ser coibida a todo instante, como é mostrado no texto com as falas dos professores, repreendendo os comportamentos infantis, e a resposta das crianças, transgredindo para brincar. Embora não estejamos minimizando ou descartando as ações que podem desencadear brigas de verdade, procuramos enfatizar, neste estudo, que a construção e o desenvolvimento desses tipos de brincadeiras não significam que as crianças estavam agindo com indisciplina, mas como uma forma particular de socialização, ou, podemos dizer, uma aprendizagem para a não violência, pois elas mesmas criam códigos e limites que conseguem demarcar essa agressividade em um contexto lúdico. Dentro de uma perspectiva de violência desacelerada, de imersão na fantasia, de brincar com a violência, de romper com o cotidiano, identificamos uma possibilidade de esse fenômeno se manifestar.

Então, por que não proporcionamos mais espaços na Educação Física para possibilidades de criações e de momentos autorais das crianças?

A Educação Física, compreendida como uma área de conhecimento que potencializa o processo educativo com a vivência, a experiência, o diálogo e as trocas de saberes relacionadas diretamente com o movimento na Educação Infantil, legitima como um momento de a criança brincar com a linguagem corporal. Este estudo mostrou que uma das formas diferentes de materializar a brincadeira foi com a dimensão lúdico-agressiva. Foi possível desvelar que 0 faz de conta permeia essas brincadeiras e que é nos momentos coletivos e em acordo com os demais integrantes que surgem elementos lúdico-agressivos em suas produções brincantes, pois as crianças sempre estão simulando e representando aspectos de sua realidade.

Em termos pedagógicos, sugere-se que o professor contextualize, em suas aulas, as pistas brincantes deixadas pelas crianças para aproveitar as suas ações criativas e imaginativas. O papel das brincadeiras lúdico-agressivas não está em propor um conteúdo exclusivo sobre isso, mas em possibilitar um processo engendrado no compartilhar da cultura lúdica infantil, na socialização das brincadeiras e no fomento à fantasia e à imaginação que é própria da criança.

Então, uma possibilidade prática pode ser trabalhar com brincadeiras historiadas, envolvendo as crianças no contexto do faz de conta, propondo uma aula, por exemplo, baseada na dimensão simbólica direcionada à mídia, na qual o objetivo seja desenvolver uma prática pedagógica com o conteúdo "desenhos animados", convidando-as a brincar com alguns personagens e seus enredos, que habitam o cotidiano lúdico da Educação Infantil, e também proporcionar um espaço para que a inventividade das crianças aflore e ganhe forma.

Portanto, permitir que, na Educação Infantil, a criança possa usufruir da prerrogativa de ser um sujeito de direitos só é possível se considerarmos como plano de fundo a centralidade, a produção de cultura e o protagonismo infantil. Só assim conseguiremos alcançar outra leitura sobre as brincadeiras lúdico-agressivas no cotidiano escolar. Isso nos sugere reconhecer a perspectiva da criança, bem como a valorização de suas racionalidades, conduzindo-nos a considerar outras formas de expressividade infantil que pulsam das experiências brincantes. 


\section{REFERÊNCIAS}

BARBOSA, Raquel Firmino Magalhães. Influências brincantes: um estudo sobre a cultura lúdica infantil e o desenho animado. 2011. 141f. Dissertação (Mestrado em Educação) - Instituto de Educação, Universidade Federal de Mato Grosso, Cuiabá, 2011.

BRASIL. Ministério da Educação. Base Nacional Comum Curricular. Brasília, 2016.

BROUGÈRE, Gilles. Brinquedo e cultura. 7. ed. São Paulo: Cortez, 2008.

CANDREVA, Thábata et al. A agressividade na educação infantil: o jogo como forma de intervenção. Pensar a Prática, v. 12, n. 1, p. 1-11, abr. 2009.

CERTEAU, Michel. A invenção do cotidiano. 8. ed. Petrópolis: Vozes, 1994.

CORSARO, William. A. Sociologia da infância. Porto Alegre: Artmed, 2011.

CORSARO, William. Reprodução interpretativa e cultura de pares. In: MULLER, Fernanda; CARVALHO, Ana Maria Almeida (Org.). Teoria e prática na pesquisa com crianças: diálogos com William Corsaro. São Paulo: Cortez, 2009. p. 31-50.

DADOUN, Roger. A violência: ensaio acerca do homo violens. Tradução de Pilar Ferreira de Carvalho e Carmem de Carvalho Ferreira. Rio de Janeiro: Difel, 1998.

FARIA, Ana Lúcia Goulart; FINCO, Daniela (Org.). Sociologia da Infância no Brasil. Campinas: Autores Associados, 2011.

FARIAS, Mayrhon José Abrantes; WIGGERS, Ingrid Dittrich; VIANA, Raimundo Nonato. O lúdico e a violência nas brincadeiras de luta: um estudo do "se movimentar" das crianças em uma escola pública de São Luís do Maranhão - Brasil. HOLOS, v. 5, p. 98-111, dez. 2014.

FINCO, Daniela; OLIVEIRA, Fabiana de. A sociologia da pequena infância e a diversidade de gênero e de raça nas instituições de educação infantil. In: FARIA, Ana Lúcia Goulart; FINCO, Daniela (Org.). Sociologia da infância no Brasil. Campinas: Autores Associados, 2011. p. 55-80.

FREIRE, João Batista. 0 jogo: entre o riso e o choro. 2. ed. Campinas: Autores Associados, 2005.

JONES, Gerard. Brincando de matar monstros: por que as crianças precisam de fantasia, videogames e violência de faz-de-conta. São Paulo: Conrad Ed. do Brasil, 2004.

LIRA, Silva Pablo. Geografia do crime: estudo do índice de violência criminalizada (IVC) e da tipologia socioespacial. E-Metropolis, v. 6, n. 23, p. 15-23, 2015.

MORIN, Edgar. 0 enigma do homem: para uma nova antropologia. Rio de Janeiro: Zahar, 1975.

PEDROSA, Maria Isabel; CARVALHO, Ana Maria Almeida. Análise qualitativa de episódios de interação: uma reflexão sobre procedimentos e formas de uso. Psicologia: Reflexão e Crítica, v. 18, n. 3, p. 431-442, 2005.

SUTTON-SMITH, Brian. The ambiguity of play. $2^{\text {th }}$ ed., Cambridge: Harvard University Press, 2001.

ZALUAR, Alba. Um debate disperso: violência e crime no Brasil da redemocratização. São Paulo em Perspectiva, São Paulo, v. 13, n. 3, p. 3-17, 1999. 